\title{
SCREENING AND ASSESSMENT OF CARDIAC AU- TONOMIC NEUROPATHY IN LONG STANDING TYPE 2 DIABETIC WOMEN
}

\author{
Byy \\ Wael Refaie \\ From
Cardiology Department \\ Mansoura Faculty of Medicine
}

\begin{abstract}
Background : Patients with long standing DM undergoing surgical interventions are put under great challenge as they may have cardiovascular and/or cardiac autonomic neuropathy (CAN). CAN is serious, often overlooked and under diagnosed, with possible arrhythmias and silent ischemia that threaten life. Objectives: Screening for one of the under diagnosed high risk problem by assessment of CAN in long standing type 2 diabetic women undergoing stressful situations. Study design: Cross section study. Patients and methods: 100 type 2 diabetic women scheduled for major surgery were assessed by the autonomic function tests. CAN was assessed by analyzing $\mathrm{HR}$ variations during three standard tests (deep breathing, lying
\end{abstract}

to standing and valsalva maneuver). Sympathetic functions were assessed by checking orthostatic hypotension. The CAN score of each patient was analyzed. Continuous 24 hours ECG monitoring (Holter) to evaluate arrhythmia, QTc and QTd. Transthoracic Doppler echocardiography, stressing on LVH, diastolic and systolic dysfunctions were carried out. Cases were classified as mild (with only one abnormal test) or severe CAN when 2 or more abnormal function tests were present. Exclusion criteria include any systemic illness that can affect the study results or the autonomic functions, smoking, hypertension and cases with evident ischemia. Results: CAN was detected in $70 \%$ of the studied cases, and $70 \%$ was severe CAN. Postural hypotension was detected MANSOURA MEDICAL JOURNAL 
in $34 \%$ of the studied cases. QTC prolongation and QT dispersion were frequent. ECG and Doppler echocardiography changes of LVH were more prevalent among patients with CAN. Diabetics with CAN were significantly older had longer duration of DM and higher $\mathrm{HbA1-c}$, higher pulse pressure, triglyceride, uric acid and urinary albumin execration rate. They also had significant increased LVM index and diastolic dysfunction. Conclusion: Middle aged women with long standing diabetes are vulnerable to CAN with postural hypotension and prolonged QTc intervals, QT dispersion, and increased LVMI. Identification of CAN is crucial to exercise prevention against hazards of $\mathrm{CV}$ insults during stressful situation and cases with severe CAN may be in need for CAD screening preoperatively.

Key word : cardiac autonomic neuropathy.

Abbreviations: CAN: Cardiac autonomic neuropathy, LVH: Left ventricular hypertrophy, DM: Diabetes mellitus, HTN: Hypertension.

\section{INTRODUCTION}

Autonomic neuropathy, although not rare, is one of the most insidious complications of diabetes mellitus
(DM) especially if long standing and poorly controlled. Cardiac autonomic neuropathy (CAN) is often overlooked both in diagnosis and treatment simply because there is no widely accepted single approach to its diagnosis (1). CAN embraces exercise intolerance, intraoperative cardiovascular liability, orthostatic syndromes and silent myocardial ischemia $(2,3,4)$. These clinical manifestations can result in life threatening outcome which unquestionably associate the presence of CAN with the increased risk of $\mathrm{CV}$ morbidity and mortality in DM.

In Eurodiab prospective study (2001) CAN was among the strongest risk markers of future total and CV mortality exceeding the effect of traditional risk factors as age, obesity, hypertension, dyslipidemia, inflammatory and prothrombotic emerging cardiac risk factor $(4,5)$. In a Meta analysis of 12 published studies Vinik et al (2003) (6) reported a constant association between CAN and silent myocardial ischemia and in DIAD study, CAN was a stronger predictor of silent ischemia and subsequent cardiac events (7).

QTc interval and QTd have been 
considered as a marker of cardiac autonomic dysfunction and have been demonstrated as an independent predictor of CV mortality and all cause mortality risk in type $2 \mathrm{DM}$ patients (4). Combined abnormality in HRV and QT index was a strong predictor of mortality independent of conventional risk factor $(8,9)$.

Action to Control Cardiovascular Risk in Diabetes (ACCORD trial 2010) in the presence of CAN at baseline was an independent contributor to the higher CV mortality risk in both the intensive and standard glycemic arm treatment. Individuals with baseline CAN were two times more likely to die compared with individuals without CAN $(10,11)$. A lot of attention has been given to the CV aspect of autonomic dysfunction especially with the view regarding very tight glycemic control with increased mortality ACCORD trial (12) attributed increased mortality to hypoglycemia induced arrhythmias (1).

There is no widely accepted single approach to the diagnosis of CAN, however during the 1970s Ewing et al (1980) (13), advised a number of simple bedside tests of short term RR difference to detect CAN including changes in RR with deep breathing, RR response to standing which induce reflex tachycardia followed by bradycardia and Valsalva ratio which evaluates cardiovagal function in response to standard increase in intrathorathic pressure.

Orthostatic hypotension with its many troublesome symptoms ranging from light headedness to near syncope that may be associated with poor quality of life with fall in systolic $\mathrm{BP} \geq 20 \mathrm{mmHg}$ and $\geq 10 \mathrm{mmHg}$ in diastolic BP during 3 minutes of standing and resolving with sitting or lying down is characteristic of CAN (14, 15).

The clinical symptoms of CAN may be late, however subclinical CAN manifest as changes in HRV may be detected within one year of diagnosis of type $2 \mathrm{DM}$ (16).

Pop Bussi (2010) (17), reported that screening for CAN revealed that it ranges from as low as $2.5 \%$ (DCCT) to as high as $90 \%$ in long standing DM and should be instituted at diagnosis of type $2 \mathrm{DM}$ and after 5 years of diagnosis of type 1 (18). Vinik and Ziegler (2007) (19), re-

MANSOURA MEDICAL JOURNAL 
ported that, detection of CAN is a must before exposing patients with long standing DM to stressful situation and also before planning exercise. Diabetics must be tested with a cardiac stress test before undergoing an exercise program. Patients with CAN need to rely on their perceived exertion and not heart rate to avoid the hazardous levels of exercise intensity (19).

Aims : Screening and assessment of cardiac autonomic dysfunction in middle aged women with long standing type 2 DM who are going to be exposed to stress in the form of major surgery.

Design : Cross- section study.

Subjects and Methods : The studied cases included one hundred and six women who are known to be diabetics and were under oral hypoglycemic agents (70 cases) and 36 cases were under combined insulin and sulphonylurea. All were receiving metfornin $1.7 \mathrm{gm} /$ day. Six cases did not complete the study for unknown reasons and only 100 cases completed the study. Their age ranged from 40 to 60 years (mean $52.4 \pm 3.7$ years). The studied cases had no polys symptoms. The mean duration of DM was $10 \pm 2$ years ranging from (6- 14 years). BMI ranging from 25.1 to 29.2 (mean $27.1 \pm 1.1)$.

All medications that can affect the study results or the autonomic functions were withhold during and one week preceding the clinical assessment of autonomic functions.

Examinations were undertaken in the morning at least 2 hours after a light breakfast and no caffeine was allowed. The patients were asked about symptoms suggestive of autonomic neuropathy, postural hypotension and myocardial ischemia.

Diabetic complications as retinopathy were checked and peripheral neuropathy, sudomotor neuropathy was stressed upon. Peripheral neuropathy and sudomotor neuropathy were detected clinically by monofilament and dryness of the feet. Clinical examination, with stress on heart rate, SBP, DBP, pulse pressure was undertaken, Testing of autonomic parasympathetic dysfunction was assessed by HRV testing (heart rate ECG RR intervals on resting, standing, respiration and valsalva). Heart rate variability was calculated from 
the RR interval using short continuous ECG recording. Continuous 24 hours ECG monitoring (Holter) was also used to evaluate ischemia, arrhythmia, QTc intervals and QTd. Cases with evident ischemia or arrhythmias were not included. The resting 12 lead ECG was also undertaken to show beside HRV evidences of LVH and/or ischemia. Prolongation of the QTc interval $>460 \mathrm{~ms}$, and QTd > $10 \mathrm{~ms}$ were considered as evidences of HRV. Flattening of $T$ wave and ST segment depression were considered as evidences of myocardial ischemia. Cases with angina ECG, Holter monitor evidences of ischemia were not included in the screening study.

Testing for sympathetic dysfunction by postural hypotension in supine and after standing for 3 minutes was undertaken with the standard mercury sphygmomanometer. The measurement in the supine position was taken after at least 15 minutes of rest and measurement in standing position was taken at the third minute of standing.

Transthoracic Doppler echocardiography was done stressing on LVMI, diastolic and systolic dysfunc- tions were carried out.

Biochemical studies were undertaken stressing on blood glucose, fasting and post 75 gm glucose challenge together with $\mathrm{HbA} 1-\mathrm{c}$, serum creatinine, plasma cholesterol, triglyceride, serum uric acid and 24 hours urine albumin excretion.

The prevalence and the severity of CAN was assessed according to the number of autonomic function tests of Ewing's methodology, and the CAN score in each patient was analyzed.

Subclinical CAN cases or mild CAN with only one abnormal function test were compared to severe CAN cases (2 or 3 abnormal autonomic function).

The study protocol was approved by the scientific committee of Mansoura Faculty of Medicine and informed consents were obtained.

Exclusion criteria : Systemic illness that can affect the study results or the autonomic functions as $\mathrm{CHF}$, CAD, arrhythmia, renal, hepatic impairment, HCV infection, severe anemia, thyroid dysfunction, smoking,

MANSOURA MEDICAL JOURNAL 
concomitant treatment with anticholinergic agents, adrenergic antagonists, vasoconstrictive agents and patients with $B P \geq 140 / 90 \mathrm{mmHg}$ on two occasions 2 weeks apart were not included.

Statistical analysis : was performed by using the statistical package for social science program (SPSS) version "16". The qualitative data were presented as frequency and percentages. The quantitative data were examined by using Kalmogrov-Smirnov test to test for normal distribution of the data and when parametric, expressed as mean and standard deviation. Student $t$ test was used, to test for difference in normally distributed quantitative data between the two groups. MannWhitney- $\mu$ test was used for comparison between two groups when data are not normally distributed. Significance was considered when $P$ value less than 0.05 .

\section{RESULTS}

The prevalence of CAN as assessed by signs of autonomic neuropathy including $\mathrm{HRV}$ tests $\mathrm{E} / \mathrm{I}$ ratio (expiration to inspiration) standing to lying flat, valsalva maneuver, were $70 \%$ (20 cases with single HRV testing, 26 cases with $3 \mathrm{HRV}$ testing, and 24 cases with moderate CAN where two HRV tests were present).

Postural hypotension was detected in $34 \%$ of the studied cases and mean pulse pressure were significantly elevated in diabetic with CAN when compared to those without CAN $(P<0.01)$.

Prolonged QTC (> $460 \mathrm{~ms}$ ) in $42 \%$ of the whole studied cases and $60 \%$ of the CAN cases and significantly increased QTd (> $10 \mathrm{~ms}$ ) in the CAN group when compared to the non CAN group as evident by the continuous 24 hrs ECG Holter monitoring.

Women with DM and CAN were significantly older with significant longer duration of uncontrolled DM with insignificant differences in BMI.

There was no significant difference in the prevalence of CAN in relation to the method of controlling hyperglycemia (oral versus combined 
oral hypoglycemic and insulin).

Symptoms suggestive of CAN in other systems, mainly urogenital were evident in the CAN group $(P<0.04)$. Peripheral neuritis detected by monofilament with dryness of their feet $(P<0.01)$. SBP, DBP and the mean pulse pressure were significantly higher in the CAN group $(P<$ 0.001).

Transthoracic echo Doppler revealed presence of mild LVH (LV wall mass index $\geq 126 \mathrm{gm} / \mathrm{m} 2$ in $70.01 \%$ of CAN versus $33.3 \%$ in the non CAN group $\mathrm{P}<0.001$ ) and significant abnormal relaxation pattern $(E / A<1)$ with preserved LV systolic functions.

Significantly higher BG level and $\mathrm{HbA1-c}$ in the CAN group was observed, with significant hypertriglyceridemia and elevation in uric acid in the CAN group. The urinary albumin excretion in the CAN was significantly elevated than in non CAN group $(P<0.01)$.Comparing the studied parameters in relation to the severity of CAN showed insignificant changes apart from significant older age, more postural hypotension, $\mathrm{HbA1-c}$, serum creatinine, urine albumin excretion and QTc. Signs of LVH and QTd revealed borderline significant increase in severe CAN cases. 
Table (1): Clinical findings in diabetes with CAN versus diabetics without CAN

\begin{tabular}{|c|c|c|c|c|c|}
\hline & $\begin{array}{l}\text { Present CAN } \\
\text { No. } 70 \text { cases }\end{array}$ & $\%$ & $\begin{array}{l}\text { Absent CAI } \\
\text { No. } 30 \text { cases }\end{array}$ & $\%$ & $\mathbf{P}$ \\
\hline Age (years) & $54.4 \pm 6.1$ & & $48.6 \pm 4.1$ & & $<0.001$ \\
\hline BMI(Kg/ m2) & $26.3 \pm 1.2$ & & $26 \pm 1.1$ & & 0.226 \\
\hline Duration Of DM & $9.9 \pm 3.1$ & & $7.3 \pm 1.1$ & & $<0.001$ \\
\hline Resting Heart Rate & $94 \pm 8$ & & $92 \pm 6$ & & 0.172 \\
\hline Postural hypotension & 34 cases & $48.57 \%$ & 2 cases & $6.66 \%$ & $<0.001$ \\
\hline $\begin{array}{l}\text { Symptoms suggestive of } \\
\text { CAN in other systems } \\
\text { - gastrointestinal } \\
\text { - Urogenital } \\
\text { - Sudomotor (dry feet) }\end{array}$ & $\begin{array}{l}4 \text { cases } \\
20 \text { cases } \\
8 \text { cases }\end{array}$ & $\begin{array}{c}7.1 \% \\
28.6 \% \\
11.4 \%\end{array}$ & $\begin{array}{l}1 \text { case } \\
3 \text { cases } \\
3 \text { cases }\end{array}$ & $\begin{array}{l}3.3 \% \\
10 \% \\
10 \%\end{array}$ & $\begin{array}{c}0.88 \\
0.044 \\
0.84\end{array}$ \\
\hline Peripheral neuritis & 56 cases & $80 \%$ & 6 cases & $20 \%$ & $<0.001$ \\
\hline Dry skin & 42 cases & $60 \%$ & 3 cases & $10 \%$ & $<0.001$ \\
\hline SBP & $130 \pm 5$ & & $120 \pm 5$ & & $<0.001$ \\
\hline DBP & $80 \pm 4$ & & $75 \pm 5$ & & $<0.001$ \\
\hline Mean pulse pressure & $50.5 \pm 3$ & & $45.5 \pm 2$ & & $<0.001$ \\
\hline $\begin{array}{l}\text { Treatment of DM } \\
\text { - Oral } \\
\text { - Combined oral and insulin }\end{array}$ & $\begin{array}{l}21 \text { cases } \\
49 \text { cases }\end{array}$ & $\begin{array}{l}30 \% \\
70 \%\end{array}$ & $\begin{array}{l}9 \text { cases } \\
21 \text { cases }\end{array}$ & $\begin{array}{l}30 \% \\
70 \%\end{array}$ & $\begin{array}{l}1 \\
1\end{array}$ \\
\hline
\end{tabular}

Table (2): Biochemical findings in Diabetes with CAN versus diabetics without CAN

\begin{tabular}{|l|l|l|c|}
\hline & $\begin{array}{l}\text { Present CAN } \\
\text { No. 70 cases }\end{array}$ & $\begin{array}{l}\text { Absent } \\
\text { CAN } \\
\text { No. 30 cases }\end{array}$ & P \\
\hline FBG mgm/dl & $180 \pm 10$ & $138.6 \pm 4.1$ & $<0.001$ \\
\hline $\begin{array}{l}\text { Post 75 gm glucose challenge } \\
\text { mgm/dl }\end{array}$ & $310 \pm 9$ & $260 \pm 1.1$ & $<0.001$ \\
\hline HbA1-c\% & $10.2 \pm 1.1$ & $9.2 \pm 1.1$ & $<0.001$ \\
\hline S. cholesterol mgm/dl & $198 \pm 16$ & $193 \pm 30$ & 0.39 \\
\hline S. Triglyceride mgm/dl & $189 \pm 11$ & $180 \pm 8.0$ & $<0.001$ \\
\hline S. Uric acid mgm\% & $6.9 \pm 1.2$ & $6.1 \pm 1.9$ & 0.035 \\
\hline S. Creatinine mgm & $1 \pm 0.35$ & $1.1 \pm 0.2$ & 0.074 \\
\hline $\begin{array}{l}\text { Urine 24 hr alb excretion } \\
\text { mg/24h }\end{array}$ & $130 \pm 1.2$ & $105 \pm 1.1$ & $<0.001$ \\
\hline HB gm\% & $10.9 \pm 0.2$ & $10.8 \pm 0.3$ & 0.097 \\
\hline S. TSH & $1.8 \pm 0.4$ & $1.7 \pm 0.5$ & 0.334 \\
\hline
\end{tabular}

Table (3): Prevalence of CAN by the different assessment tests.

\begin{tabular}{|l|l|l|}
\hline Method & No of cases & percentage \\
\hline HRV: E/I ratio & 20 & $20 \%$ \\
\hline HRV: Standing to lying flat & 20 & $20 \%$ \\
\hline HRV:Valsalva maneuver & 30 & $30 \%$ \\
\hline PosturaIhypotension & 34 & $34 \%$ \\
\hline QTc prolongation $>\mathbf{4 6 0} \mathbf{~ m m}$ & 42 & $42 \%$ \\
\hline QTd>10ms & 42 & $42 \%$ \\
\hline
\end{tabular}

Vol. 42, No. 1 \& 2 Jan. \& April, 2013 
Table (4): ECG findings and transthoracic Doppler Echocardiography in Diabetes with CAN versus diabetics without $\mathrm{CAN}$

\begin{tabular}{|c|c|c|c|c|c|}
\hline & $\begin{array}{l}\text { Present CAI } \\
\text { No. } 70 \text { cases }\end{array}$ & $\%$ & $\begin{array}{l}\text { Absent CA } \\
\text { No. } 30 \text { cases }\end{array}$ & $\%$ & $\mathbf{P}$ \\
\hline QTe interval $\geq 460 \mathrm{~ms}$ & 42 cases & $60 \%$ & 10cases & $33.3 \%$ & 0.01 \\
\hline QTd $\geq 10 \mathrm{~ms}$ & 42 cases & $60 \%$ & 10 cases & $33.3 \%$ & 0.01 \\
\hline Evidence of LVH & 28 cases & $40 \%$ & 3 cases & $10 \%$ & 0.003 \\
\hline LVM index $\geq 126 \mathrm{gm} / \mathrm{m} 2$ & 50 cases & $70.1 \%$ & 10 cases & $33.3 \%$ & $<0.001$ \\
\hline E/A ratio $<1$ & 40 cases & $57.1 \%$ & 10 cases & $33.3 \%$ & 0.029 \\
\hline$E F>60 \%$ & 60 cases & $85.7 \%$ & 26 cases & $86.6 \%$ & 0.599 \\
\hline
\end{tabular}

Table (5): Clinical, biochemical and ECG findings of cases with subclinical mild CAN versus severe CAN cases

\begin{tabular}{|l|l|l|c|}
\hline & $\begin{array}{l}\text { Mild CAN } \\
\mathbf{1 8} \text { cases }\end{array}$ & $\begin{array}{l}\text { Severe CAN } \\
\mathbf{5 2} \text { cases }\end{array}$ & P \\
\hline Age (years) & $56.9 \pm 2.1$ & $55.1 \pm 2.5$ & 0.003 \\
\hline BMI(Kg/ m2) & $26.6 \pm 1.2$ & $27.2 \pm 1.1$ & 0.066 \\
\hline WC & $95 \pm 3.5$ & $96 \pm 4.1$ & 0.321 \\
\hline Duration Of DM & $9.8 \pm 3.1$ & $9.9 \pm 1.1$ & 0.893 \\
\hline SBP & $138 \pm 5$ & $140 \pm 5$ & 0.148 \\
\hline DBP & $88 \pm 4$ & $90 \pm 5$ & 0.091 \\
\hline Mean pulse pressure & $74.5 \pm 4$ & $75.5 \pm 3$ & 0.335 \\
\hline Resting Heart Rate & $96 \pm 8$ & $39 \pm 6$ & 0.149 \\
\hline Postural hypotension & 2 cases $11.1 \%$ & $10.3 \pm 1.1$ & $<0.001$ \\
\hline HbA1-c & $8.9 \pm 1.1$ & $210 \pm 8.9$ & $<0.001$ \\
\hline S. cholesteroI mgm/dI & $205 \pm 10.2$ & $201 \pm 7.1$ & 0.068 \\
\hline S. Triglyceride mgm/dl & $199 \pm 8.1$ & $7.1 \pm 2.2$ & 0.355 \\
\hline S. Uric acid mgm\% & $6.6 \pm 1.2$ & $1.2 \pm 0.1$ & 0.233 \\
\hline S. Creatinine mgm & $1.0 \pm 0.2$ & $200 \pm 1.2$ & $<0.001$ \\
\hline Urine 24 hr alb excretion & $190 \pm 1.2$ & $460.1 \pm 10.1$ & $<0.001$ \\
\hline QTc interval & $448.1 \pm 9.9$ & 30 cases $57.7 \%$ & $<0.001$ \\
\hline QTd $>\mathbf{1 0}$ ms & 6 cases $33.3 \%$ & 0.076 \\
\hline
\end{tabular}




\section{DISCUSSION}

It was aimed in the present screening study to evaluate the CAN in middle aged women with long standing diabetes scheduled for stressful situation in the form of major surgery. Detection of CAN preoperatively is necessary as such patients are vulnerable to perioperatve cardiovascular instability with a greater decline in heart rate and BP during induction of anesthesia and more severe hypothermia $(19,3)$.

In the present study, the prevalence of CAN as detected by Ewings et al 1970s proposals of heart rate variability tests (Ewings et al 1980) was high $(70 \%)$. As the determination of CAN is usually based on a battery of autonomic function test and as the proceeding from a consensus conference (1992) (20), recommended three tests. In the present study, the golden standard clinical autonomic testing (21) was followed (Expiration/inspiration ratio, standing to lying flat and valsalva maneuver and postural hypotension)

The prevalence of CAN ranged from $20 \%$ to $42 \%$ according to the way of detecting HRV state being highest $(30 \%)$ by the valsalva ma- neuver procedure and lowest (20\%) by the diminished expiration to inspiration ratio (E/I ratio) and by standing to laying flat. The scoring of CAN was calculated, where more than one fourth $(26 \%)$ had $\geq 3$ positive tests and $24 \%$ had $\geq 2$ positive. This is in accordance with Katsilamborus et al (2011) (1), who found that autonomic neuropathy and CAN are not at all rare, but are often overlooked.

The prevalence of CAN ranged from as low as $2.5 \%$ (DCCT) (17) to as high as $90 \%$ in long standing DM and in $69 \%$ of treatment induced neuropathy (22). In the present study the valsalva ratio was $30 \%$ and E/I ratio was $20 \%$. Our results are not in accordance with England and coworkers (2009) (23), who found that HRV with deep breathing is the most widely used test of cardiovagal parasympathetic dysfunction. Cardiovascular sympathetic function was assessed by measuring the BP response to orthostatic changes (24, 25) and was detected in $34 \%$ of the studied cases.

The prevalence of CAN in the present study is higher than that of Zeigler et al 1992 (26), who by using HRV tests found that $34.3 \%$ of type 
2 DM patients had abnormal functions. Similar to Cabezas- Cerrato et al 2009 (27), the HR response to deep breathing in the present study was the least evident among the studied cases.

In the present study, the studied cases were all females this could avoid gender related difference in biochemical and hematological values $(28,29)$. CAN was more prevalent in diabetic of longer duration, older age those with more pulse pressure, higher serum triglycerides and with more elevated $\mathrm{HbA} 1-\mathrm{c}$. Kodama et al (2012) (30), in a Meta analysis study described the association of pulse pressure as a cardiovascular risk in DM. Makimattila et al (2000) (31), found that poor glycemic control was the most important independent predictor of decrease in all measures of absolute power of HRV.

Our findings are also in agreement with those of Voulgari et al 2011(21) who mentioned that in type 2 DM patients, CAN has been independently associated with elevated $\mathrm{BP}$, hyperglycemia, longer diabetes duration, dyslipidemia and the presence of microvascular complications (32, 21). Katsilambors et al (2011) (1) reported the association of high serum uric acid level and sundomotor dysfunction in patient with type $2 \mathrm{DM}$ and CAN. In the present study similarly serum uric acid showed significant differences.

Symptoms of orthostatic intolerance and gastrointestinal function, urinary frequency, nocturia and anhydrosis were reported more frequently in diabetics with CAN. This is in line with Gibons and Freeman (2011) (33), although in the present study only the urogenital symptoms were significantly more frequent in CAN group.

Peripheral neuropathy was present in $80 \%$ of the examined cases. This is in agreement with Vinik and Ziegler (2007) (34), Gandhi et al (2010) (35) who found that combined indices of autonomic and peripheral neurological dysfunction is associated with earlier CAN detection (36, 37). In the EURODIAB (24) prospective complication study peripheral and autonomic neuropathy was among the strongest risk markers exceeding the effects of the traditional risk factors.

Orthostatic hypotension was dem- 
onstrated in $34 \%$ of the whole studied cases and in $60 \%$ of the CAN group. Orthostatic symptomatology as light headedness, dizziness, fatigability, faintness on standing was very frequent $(60 \%)$. However no reported cases of clear or near syncope were reported. Orthostatic hypotension in CAN is secondary to efferent sympathetic vasomotor denervation causing reduced vasoconstriction of the splanchinic and other peripheral bed (20).

In the present study the resting heart rate in the CAN group was around $100 \mathrm{bpm}$ but was insignificantly rapid than in the non CAN group. This is in line with Pop-Bussi (2010) (17) who stated that increased resting heart rate is not a reliable diagnostic criterion for CAN in the absence of other signs.

In the present study QTc prolongation and the more prevalent QT dispersion, are in agreement with Voulgari et al (2011) (4). QTc interval was considered as a marker of cardiac autonomic dysfunction and is significantly associated with LVH (4). The increase in the number of the abnormal CAN function tests increase the risk more (38). Pappach- en et al (2008) (39) concluded that QTc interval can be used to diagnose CAN and the combined abnormality of HRV, QTC and QTd were strong predictors of mortality independent of conventional risk factors $(40,41)$.

Prolongation of QTc interval was detected in $60 \%$ of the CAN cases. This coincides with the finding of Lombardi (2002) (42). LVH was significantly manifest in the CAN group in comparison to the non CAN group.

In the present study QTc interval prolongation (> $440 \mathrm{~ms}$ ) has been associated with increased age and duration of DM, SBP, DBP, mean pulse pressure and severity of autonomic neuropathy. This is in accordance with the finding of Ewing et al (1991) (43) and Veglio et al 2000 (44).

Comparing mild CAN cases and severe CAN cases revealed some clinical, biochemical, electrocardiographic and echocardiographic significant differences including; older age, more postural hypotension, elevated $\mathrm{HbA1-c}$, serum creatinine, urine 24 albumin excretion and more frequent QTC prolongation which 
may impose more cardiovascular risk.

\section{CONCLUSION}

CAN in women with type $2 \mathrm{DM}$ are common. Detection of CAN irrespective of its scoring in patient with DM is of importance and can help to exercise more precautions during their diabetic management. As patients with prolonged QT intervals are at higher risk of sudden cardiac death, cases with sever CAN have to be screened for CAD preoperatively and special clinic for cardiac autonomic neuropathy may be warranted.

\section{REFERENCES}

1- Nicholas L. Katsilambros, Andrew J. (2011) : Boulton, Nicholas Tentolouris, Alexander Kokkinos, and Stavros Liatis. Autonomic Neuropathy in DiabetesMellitus and Obesity: An Update. Experimental Diabetes Research Volume, Article ID 607309, 2 pages.

2- Maser RE, Lenhard MJ. (2007) : An overview of the effect of weight loss on cardiovascular autonomic function.
Curr Diabetes Rev. Aug;3 (3):204-11 .

3- Tesfaye S., Boulton A. J. M., Dyck P. J. (2010) : Diabetic neuropathies: update on definitions, diagnostic criteria, estimation of severity, and treatments. Diabetes Care, vol. 33, no. 10, pp. 2285-2293.

4- Christina Voulgari, Nicholas Tentolouris and Christodoulos Stefanadis. (2011) : The ECG Vertigo in Diabetes and Cardiac Autonomic Neuropathy. Experimental Diabetes Research Volume, Article ID 687624, 17.

5- Soedamah-Muthu SS, Chaturvedi N,Witte DR, Stevens LK, Porta M, Fuller JH, EURODIAB Prospective Complications Study Group. (2008) : Relationship between risk factors and mortality in type 1 diabetic patients in Europe: the EURODIAB Prospective Complications Study (PCS). Diabetes MANSOURA MEDICAL JOURNAL 
38

Care;31:1360-1366.

6- Vinik Al, Maser RE, Mitchell BD, Freeman R. (2003) : Diabetic autonomic neuropathy. Diabetes Care; 26:1553-1579.

7- Young LH, Wackers FJ, Chyun DA, Davey JA, Barrett EJ, Taillefer R, Heller GV, Iskandrian AE, Wittlin SD, Filipchuk N, Ratner RE, Inzucchi SE, DIAD Investigators. (2009) : Cardiac outcomes after screening for asymptomatic coronary artery disease in patients with type 2 diabetes: the DIAD study: a randomized controlled trial. JAMA; 301:1547-1555.

8- Rossing P., Breum L., MajorPedersen A. (2001) : Prolonged QTc interval predicts mortality in patients with Type 1 diabetes mellitus," Diabetic Medicine, vol. 18, no. 3, pp. 199- 205.

9- Stettler C,. Bearth A, Allemann. (2007) : QT interval and resting heart rate as long- term predictors of mortality in type 1 and type 2 diabetes mellitus: a 23-year follow-up. Diabetologia, vol. 50, no. 1, pp. 186-194.

10- D. Ziegler, W. Rathmann, C. Meisinger, T. Dickhaus, and A. (2009) : Mielck. "Prevalence and risk factors of neuropathic pain in survivors of myocardial infarction with pre-diabetes and diabetes. The KORA Myocardial Infarction Registry," European Journal of Pain, vol. 13, no. 6, pp. 582-587.

11- J. Calles-Escand' on, L. C. Lovato, D. G. (2010) : Simons-Morton. "Effect of intensive compared with standard glycemia treatment strategies on mortality by baseline subgroup characteristics: the action to control cardiovascular risk in diabetes (ACCORD) trial," Diabetes Care, vol. 33, no. 4, pp. 721-727.

12- Pop-Busui R., Evans G. W., Gerstein H. C. (2010) : Ef- 
fects of cardiac autonomic dysfunction on mortality risk in the Action to Control Cardiovascular Risk in Diabetes (ACCORD) trial. Diabetes Care, vol. 33, no. 7 , pp. 1578- 1584 .

13. Ewing DJ, Campbell IW, Clark BF. (1980) : Assessment of cardiovascular effects in diabetic autonomic neuropathy and prognostic implications. Ann Intern Med 92:308-311.

14- Low PA, Opfer-Gehrking TL, McPhee BR, et al. (1995) : Prospective evaluation of clinical characteristics of orthostatic hypotension. Mayo Clin Proc: 70:617-22.

15- W Singer, T L Opfer-Gehrking, B R McPhee, M J Hilz, A E Bharucha, $P$ A Low. (2003) : Acetylcholinesterase inhibition: a novel approach in the treatment of neurogenic orthostatic hypotension. See Editorial Commentary, p $1187 \mathrm{~J}$ Neurol Neurosurg Psychia- try; 74:1294-1298

16- Pfeifer MA, Weinberg CR, Cook DL, Reenan A, Halter JB, Ensinck JW, Porte D Jr. (1984) : Autonomic neural dysfunction in recently diagnosed diabetic subjects Diabetes Care; 7:447-453.

17- Pop-Busui R., Herman W. H., Feldman E. L. (2010) : DCCT and EDIC studies in type 1 diabetes: lessons for diabetic neuropathy regarding metabolic memory and natural history. Current Diabetes Reports, vol. 10, no. 4, pp. 276-282.

18- Kennedy WR, Navarro $X$, Sutherland DE. (1995) : Neuropathy profile of diabetic patients in a pancreas transplantation program. Neurology; 45:773-780.

19- Vinik Al, Ziegler D. (2007) : Diabetic cardiovascular autonomic neuropathy. Circulation; 115:387-397.

20- Consensus Committee of the MANSOURA MEDICAL JOURNAL 
40

\author{
American Autonomic So- \\ ciety and the American \\ Academy of Neurology. \\ (1996) : Consensus state- \\ ment on the definition of or- \\ thostatic hypotension, pure \\ autonomic failure, and mul- \\ tiple system atrophy. Neu- \\ rology; 46:1470.
}

21- Voulgari a C., Psallas M., Kokkinos A., Argiana V., Katsilambros N.and Tentolouris N. (2011) : The association between cardiac autonomic neuropathy with metabolic and other factors in subjects with type 1 and type 2 diabetes. Journal of Diabetes and Its Complications, vol. 25, no. 3, pp. 159-167.

22- Christopher H Gibbons, and Roy Freeman. (2010) : Treatment induced diabetic neuropathy-a reversible painful autonomic neuropathy. Ann Neurol. April ; 67 (4): 534-541. doi:10.1002/ ana. 21952.

23- England JD, Gronseth GS, Franklin G, Carter GT,
Kinsella LJ, Cohen JA, Asbury AK, Szigeti K, Lupski JR, Latov N, Lewis RA, Low PA, Fisher MA, Herrmann D, Howard JF, Lauria G, Miller RG, Polydefkis M, Sumner AJ. (2009) : American Academy of Neurology, American Association of Neuromuscular and Electrodiagnosticn Medicine, American Academy of Physical Medicine and Rehabilitation. Evaluation of distal symmetric polyneuropathy: the role of autonomic testing, nerve biopsy, and skin biopsy (an evidence-based review). Muscle Nerve; 39:106-115.

24- Kempler P., Tesfaye S., Chaturvedi N. (2001) : Blood pressure response to standing in the diagnosis of autonomic neuropathy: the EURODIAB IDDM Complications Study," Archives of Physiology and Biochemistry, vol. 109, no. 3, pp. 215-222.

25- Freeman, R. (2006) : Assess- 
ment of cardiovascular autonomic function. Clinical Neurophysiology, vol. 117, no. 4, pp. 716-730.

26- Ziegler D, DannehI K, Mu" hlen H, Spu" ler M, Gries FA. (1992) : Prevalence of cardiovascular autonomic dysfunction assessed by spectral analysis, vector analysis, and standard tests of heart rate variation and blood pressure responses at various stages of diabetic neuropathy. Diabet Med ;9: 806-814.

27- Cabezas-Cerrato J., GonzalezQuintela A., Perez- Rodriguez M. (2009) : Combination of cardiorespiratory reflex parameters and heart rate variability power spectrum analysis for early diagnosis of diabetic cardiac autonomic neuropathy. Diabetes \& Metabolism, vol. 35, no. 4, pp.305-311.

28- Giorno R, Clifford JH, Beverly S, Rossing RG. Hematology reference values. (1980) : Analysis by differ- ent statistical technics and variations with age and sex. Am J Clin Pathol; 74:765-770.

29- Hale WE, Stewart RB, Marks RG. (1983) : Haematological and biochemical laboratory values in an ambulatory elderly population: an analysis of the effects of age, sex and drugs. Age Ageing; 12:275-284.

30- Kodama S, Heianza Y, Yoshizawa S, Fujihara $\mathrm{K}$, Tanaka S, lida KT, Yachi Y, Ohashi Y, Sone H. (2012) : Association between pulse pressure and cardiovascular risk in diabetes mellitus: a meta-analysis. Diabetologia 55: supp S1S538.

31- Mäkimattila $S$, Schlenzka $A$, Mäntysaari $M$, Bergholm $\mathbf{R}$, Summanen $\mathbf{P}$, Saar $\mathbf{P}$, Erkkilä $\mathrm{H}, \mathbf{Y k i - J a ̈ r v i n e n ~} \mathrm{H}$. (2000) : Predictors of abnormal cardiovascular autonomic function measured by frequence domain analysis of heart rate variability

MANSOURA MEDICAL JOURNAL 
and conventional tests in patients with type 1 diabetes. Diabetes Care. Nov; 23(11):1686-93.

32- Valensi $P$, Pariès J, Attali JR; French Group for Research and Study of Diabetic Neuropathy. (2003) : Cardiac autonomic neuropathy in diabetic patients: influence of diabetes duration, obesity, and microangiopathic complications--the French multicenter study. Metabolism. Jul; 52(7):815-20.

33- Christopher H Gibbons, MMSc and Roy Freeman. (2010) : Treatment induced diabetic neuropathy- a reversible painful autonomic neuropathy. Ann Neurol. April ; 67 (4): 534-541.

34- Vinik A. I and Ziegler D. (2007) : Diabetic cardiovascular autonomic neuropathy.Circulation, vol. 115, no. 3, pp. 387-397.

35- Gandhi R. A, Marques J. L. B., Selvarajah D., Emery C.
J., and Tesfaye S. (2010) : Painful diabetic neuropathy is associated with greater autonomic dysfunction than painless diabetic Neuropathy. Diabetes Care, vol. 33, no. 7, pp. 1585-1590.

36- Liatis S., Marinou K., Tentolouris N., Pagoni S. (2007) : and Katsilambros N., "Usefulness of a new indicator test for the diagnosis of peripheral and autonomic neuropathy in patients with diabetes mellitus. DiabeticMedicine, vol. 24, no. 12 , pp. $1375-1380$.

37- Tentolouris N., Voulgari C., Liatis S. (2010) : Moisture status of the skin of the feet assessed by the visual test neuropad correlates with foot ulceration in diabetes. Diabetes Care, vol. 33, no. 5, pp. 1112-1114.

38- Giunti S., Bruno G., Lillaz E. Incidence and risk factors of prolonged QTC interval in type 1 diabetes: the EURODIAB prospective complications study," Diabetes 
Care, vol. 30, no. 8, pp. 2057-2063, 2007.

39- Pappachan JM, Sebastian J, Bino BC, Jayaprakash K, Vijayakumar K, Sujathan P, Adinegara LA. (990) : Cardiac autonomic neuropathy in diabetes mellitus: prevalence, risk factors and utility of corrected QT interval in the ECG for its diagnosis. Postgrad Med J. 2008 Apr;84:205-10.

40- Lykke JA, Tarnow L, Parving HH and Hilsted J. (2008) : A combined abnormality in heart rate variation and $Q T$ corrected interval is a strong predictor of cardiovascular death in type $1 \mathrm{di}-$ abetes. Scand J Clin Lab Invest; 12:1-6.

41- Ziegler D, Zentai CP, Perz S, Rathmann W, Haastert B, Do" ring $A$, Meisinger $C$, KORA Study Group. (2008) : Prediction of mortality using measures of cardiac autonomic dysfunc- tion in the diabetic and nondiabetic population: the MONICA/KORA Augsburg Cohort Study. Diabetes Care; 31:556-561.

42- Lombardi F. (2002) : Clinical implications of present physiological understanding of HRV components," Cardiac Electrophysiology Review, vol. 6, no. 3, pp. 245-249.

43- Ewing D. J., Boland O., Neilson J.M. M., Gho C. G., and Clarke B.F. (1991) : Autonomic neuropathy, QT interval lengthening, and unexpected deaths in male diabetic patients. Diabetologia, vol. 34, no. 3, pp. 182-185.

44- Veglio M., Chinaglia A, and Cavallo P. (2000) : The clinical utility of QT interval assessment in diabetes," Diabetes, Nutrition and Metabolism-Clinical and Experimental, vol. 13 , no. 6 , pp. 356-365. 